\title{
Obstacle Detector for Blind Peoples
}

\author{
M. Maragatharajan, G. Jegadeeshwaran, R. Askash, K. Aniruth, A. Sarath
}

\begin{abstract}
From the survey of WHO, 39 million people are blind all over the world. It is a quite miserable statement. The peoples who are all suffered from these visual difficulties can use this project to overcome their situations. The ultrasonic sensor used in this project plays a vital role. It detects the object in front of this with a certain range. When object is detected a buzzer sound is given to the user as an indication. While they hear this sound they can know an obstacle in front of them.

Keywords : Arduino UNO, buzzer, ultrasonic sensor.
\end{abstract}

\section{INTRODUCTION}

Since the running of daily life of blind people is very difficult. This project helps them to run their life as usual. They can make this project as a gadget or a device in their hands which detects the obstacle. This project is more efficient than the existing system with cheaper and accurate one. Here we are using arduino UNO board to perform this operation. To make the life to be as a normal one for the blind peoples this may be very helpful project for them. By making this as a gadget or a device in their hand they can easily judge an object by their own by knowing the buzzer sound. The system uses ultrasonic sensor as a wide range of field to detect an object with its higher detection range. Based on this project we take survey in our institution.

The survey includes the following:

1. What is the barrier faced in the institution?

2. What are the sufficient things needs for your daily life?

3. What assistive devices or hardware facilities available in your institution?

4. Do you think there are sufficient assistive software/hardware facilities available for you in the institution?

5. Any suggestions for the institution working for people with disabilities.

6. Are they understand about this project.

7. Any improvements needed?

\section{EXISTING SYSTEM}

Till the last few years, there are many new technologies have been developed for visually challenged peoples. But, there are a lot of limitations and restrictions on those new inventions.

Revised Manuscript Received on December 16, 2019.

M. Maragatharajan, Assistant Professor, Department of Information Technology, Kalasalingam Academy of research and education, Krishnankoil, India.

G. Jegadeeshwaran, Department of Information Technology, Kalasalingam Academy of research and education, Krishnankoil, India.

R. Aakash, Department of Information Technology, Kalasalingam Academy of research and education, Krishnankoil, India.

K. Aniruth, Department of Information Technology, Kalasalingam Academy of research and education, Krishnankoil, India.

A. Sarath, Department of Information Technology, Kalasalingam Academy of research and education, Krishnankoil, India
Shovel[1] proposed a method for the blind people. He proposed two different types of sounds. The major drawback of his work is to identification of the sound. The blind people cannot differentiate the sounds.

Yuan [2] introduced concept of active triangulation that was used in his proposed device. It will detect the object. The main disadvantage of this work is, it can only detects the object at the rate of 15 measurement/ second and also faces a surface discontinuities.

JM. Benjamin [3] proposed a three direction detectable laser cane. The direction is 45 degrees over and parallel to the ground and with sharp deepness. It is basically a hit and trial method it is used only in indoor systems. The main disadvantage in his system is it is not suitable for outdoor activities.

S. Sabarish [4] proposed a system which is similar to our project nearly, but he has an some vibrators in his device. Till it is not successful but he keeps on working on it.

MA. Espinosa \& S. Ungar [5] introduced an idea, that was more costlier than the normal one. He did not consider the poor peoples who cannot buy those things.

Pooja Sharma [6] created a device for blind people. In that case the object has been detected but within a certain range. only within that range the object can be identified. This was the major limitation in this paper.

All the above existing system cannot satisfy the exact needs of the blind peoples. They use a white cane and pet dogs which is very costlier and difficult to maintain. To overcome those limitations this project will help. Nowadays there is a lot of technologies available for the visually challenged but our project is cheaper among them.

\section{III.PROPOSED SYSTEM}

The proposed system deals with the cheaper and effective obstacle detection with a wide range of coverage. The device includes the following components:

- Arduino UNO

- Ultrasonic sensor

- Bread board

- Buzzer

- 5 mm LED: Red

- Slide Switch

- Female Header

- Male Header

- Jumper wires

- Power bank

- Some elastics and stickers

Let us see about the components in brief: 


\section{Obstacle Detector for Blind Peoples}

\section{ARDUINO UNO:}

The Arduino is an open source hardware and software that can make a user to do effective operation in it. The Arduino is a microcontroller. These microcontroller devices help in sensing and controlling the objects in the real-time situations and environment. These boards are available cheaper in the market. There are a number of inventions performed in it and still it is going on.

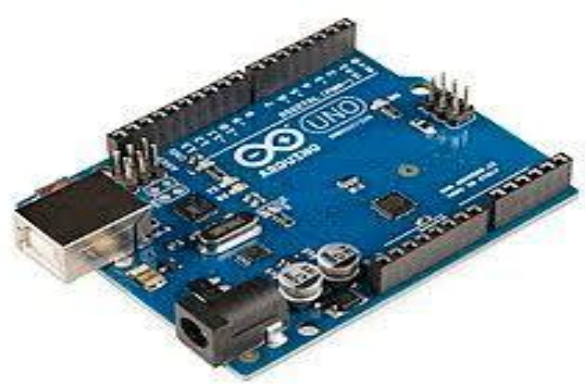

Figure1:Aduino uno

\section{ULTRSONIC SENSOR:}

The ultrasonic sensor consists of transmitter, receiver and transceiver. The transmitter convert electrical signal into soundwaves. The receiver converts the soundwaves into electrical signal again. The transceiver performs both the receiver and transmitter operations.

It also has crystal oscillators in it. It will perform the stabilization operation in the ultrasonic sensor.

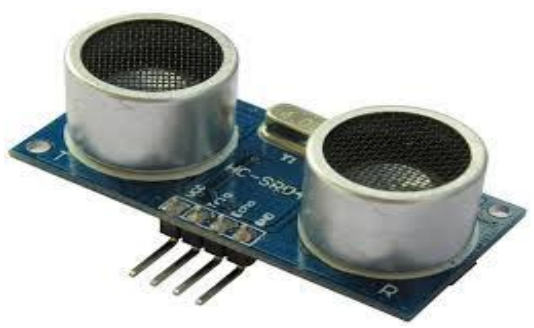

Figure 2: Ultrasonic sensor

\section{JUMPER WIRE:}

The jump wires are also known as jumper wire used to connect devices. Without soldering we can make an easier connection with devices. These are available as a set of wire that has the pin on both sides. These wires are used as making their one end connecting to the corresponding device and another end to the breadboard.

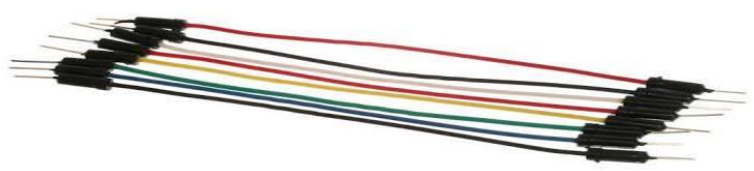

Figure 3: Jumper wires

\section{PIEZO BUZZER:}

The piezo buzzer is an electronic device which generates sound through it. The buzzer is used as an indication to the user. It is used in the car reversing system and braking system as an indication. It is based on the principle of piezoelectricity discovered in 1880 by Jacques and Pierre Curie.

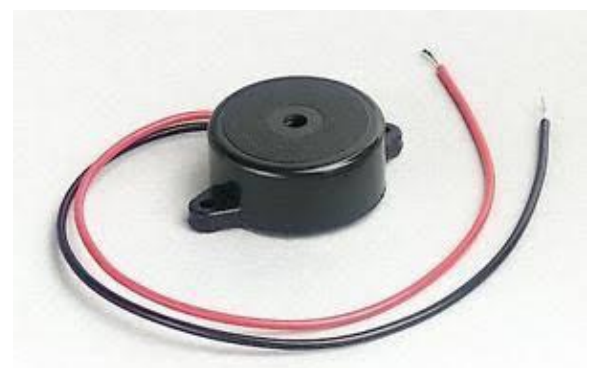

Figure 4: Piezo buzzer

\section{ARDUINO SOFTWARE:}

The Arduino is the most used programming software to perform the above-mentioned operation. Using some program in the software we can do every operation

\section{SYSTEM ARCHITECTURE:}

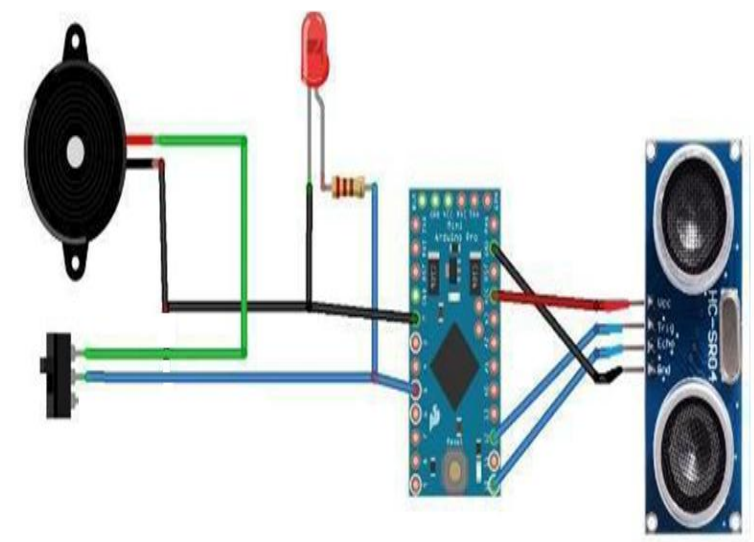

Figure 5: Circuit diagram

The Aduino is now connected with ultrasonic sensor as the primary input to the arduino. Then the output from the arduino is connected to LED and buzzer. From feeding the program to the arduino board this will perform the required operation

\section{WORKING OPERATION:}

This proposed system consists the equipment like Arduino UNO, ultrasonic sensor, bread board, buzzers for detecting the obstacles and letting the user know about the obstacle, Red LEDs, Switches, Jumper cable, power bank, Male and female header pins, some elastic and stickers to make the device wearable as a band for wearing for the users. The wiring of the device is done in a following manner. The Ground of LED, buzzer are connected to GND of the Arduino. The +ve of the LED and the middle leg of switch is connected to the Arduino pin 5. The +ve of the

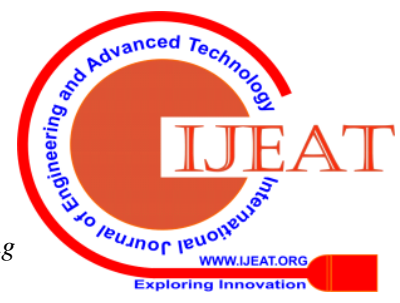


Buzzer is wired to the first leg of the switch.

The Ultrasonic sensor is wired accordingly. The Ultrasonic sensor pin VCC is connected to the Arduino pin VCC, Ultrasonic sensor pin GND is connected to the Arduino pin GND, Ultrasonic sensor pin Trig is attached to the Arduino pin 7, Ultrasonic sensor pin Echo is connected to the Arduino PIN 6. The switch used here is for selecting the mode. (Buzzer should need or not). At the end, after all the connections are done to the Arduino board upload the code to arduino board and power the other modules using a power bank or the power supply.

The Ultrasonic sensor here used as a transceiver. The ultrasonic waves are emitted by the transmitter when the objects are detected. Both the transmitter and receiver re resent inside the ultrasonic sensor. We calculate the time interval between the transmitted and received signal. The distance between the object and sensor is calculated using this.

When we increase the distance between the object and the sensor the coverage angle will decrease.

Sensor has coverage of 60 degree. Thus, the objective is to cover a wide angle to detect the obstacles with the help of the ultrasonic sensors to help the blind and make it easy for them to move around easily without any hassle. Hence, the distance calculation is calculated and the sensor detects and the further procedure of the buzzing sound to the user is carried out.

Thus, this way Third Eye for Blind will be designed for the visually impaired people and will make it very easy and convenient as it will be a wearable device and thus will help the user in travelling and detecting the obstacles while walking very easy.

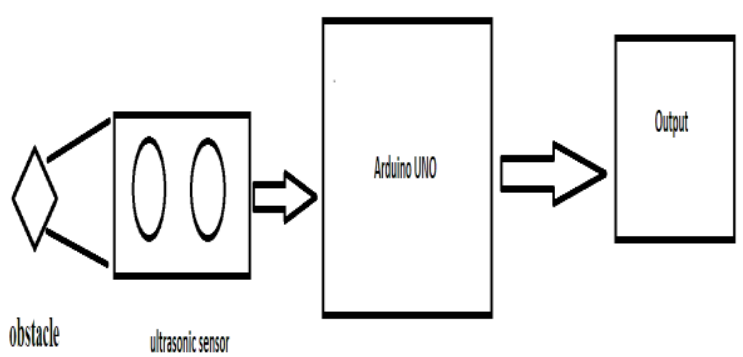

Figure 6: system module

\section{IV.RESULTS}

With the improvement of the living standards of the people, we have become so materialistic that we have forgotten how the physically disabled people live a tough life. They undergo rigorous, indifferent behavior towards them for being physically disabled. They become dependent on other people in a way for their day to day routine chores. Blind and impaired persons always depend on other people for their regular activities. Eyes are responsible for observing and listen the outside environment; dysfunction of such prime sense organ severely affects the knowledge perceiving capability of the outside environment. Therefore, going around to places in such an environment is a very big challenge because blind people cannot depend on their own eyes and thus face many difficulties. This project will help them to overcome their obstacles.

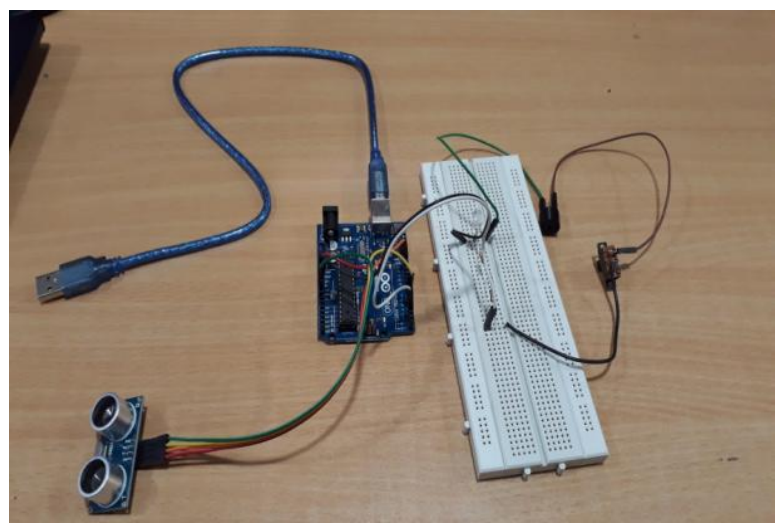

Figure 7: project at initial stage

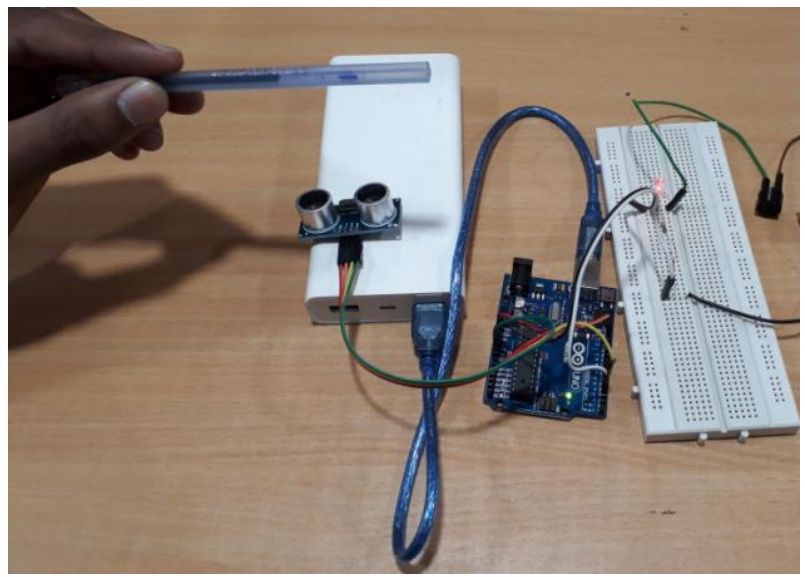

Figure 8: output when an object is detected

\section{V.CONCLUSION}

The objective of this project is Third Eye for the Blind is to design a product which is very much useful to those people who are visually impaired and those who often have to rely on others. The third eye for Blind project is an innovation which helps the blind person to move around and go from one place to another with speed and confidence by knowing the nearby obstacles using the help of the wearable band which produces the ultrasonic waves which notify them with buzz sound or vibrations. It allows the user those who are visually impaired to walk freely by detecting the obstacles. They only need to wear this device as a band or cloth on their body.

Thus, this project Arduino based obstacle detector for blind people is a new method to resolve their problems. A less complex portable, cost efficient, easy to manage an effective system with many more amazing properties and advantages are proposed to provide support for the blind. The system will be very easy to find the distance between the objects and the sensor. It can detect the objects in every directions th the blind person. Without the help of others the blind person can move from one place to other and lead their regular lives independently. 


\section{Obstacle Detector for Blind Peoples}

\section{REFERENCES}

1. S. Shovel, I Ulrich, J. Borenstien.Nav Belt and the Guide Cane, IEEE "Transactions on Robotics \& Automation". 2003; 10(1):9-20.

2. D. Yuan R. Manduchi. "Dynamic Environment Exploration Using a Virtual White Cane", Proceedings of the IEEE Computer Society Conference on Computer Vision and Pattern Recognition (CVPR), University of California, Santa Cruz, 2005, 1-7.

3. JM. Benjamin,NA. Ali, AF. Schepis. "A laser cane for the blind", Proceedings of San Diego Medical Symposium, 1973, 443-450.

4. S. Sabarish. "Navigation Tool for Visually Challenged using Microcontroller", International Journal of Engineering and Advanced Technology (IJEAT), 2013; 2(4):139-143.

5. MA. Espinosa,S. Ungar,E. Ochaíta. "Blades comparing methods for Introducing Blind and Visually Impaired People to unfamiliar urban environments.", Journal of Environmental psychology. 1998; 18:277287.

6. Pooja Sharma,SL. Shimi,S. Chatterji. "A Review on Obstacle Detection and Vision", International Journal of Science and Research Technology. 2015; 4(1):1-11.

7. AA. Tahat." A wireless ranging system for the blind long-cane utilizing a smart-phone", in Proceedings of the 10th International Conference on Telecommunications. (ConTEL '09), IEEE, Zagreb, Croatia, June. View at Scopus. 2009, 111-117.

8. D. Bolgiano, E. Meeks." A laser cane for the blind", IEEE Journal of Quantum Electronics. View at Google Scholar. 1967; 3(6):268.

\section{BIBILIOGRAPHY}

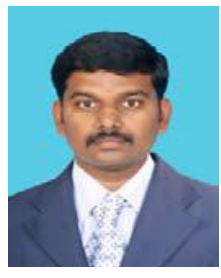

Maragatharajan $\mathrm{M}$ received his Bachelor degree in Electronics \& Communication Engineering from Anna University by 2007. He has received his Master degree in Information Technology from Kalasalingam University, 2010 and completed his Ph.D in the area of MANET. He has worked as a Project Associate in TIFAC CORE in Network Engineering, Kalasalingam University from 2007 to 2008. Currently, $\mathrm{He}$ is working as an Assistant Professor in the Department of Information Technology, Kalasalingam University. His areas of interest are Ad-hoc Networks, Wireless Networks, and Network Security.

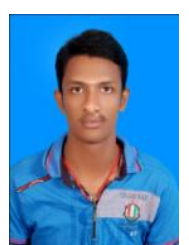

Jegadeeshwaran. G pursuing his undergraduate degree in B. Tech Information Technology from Kalasalingam Academy of Research and Education. He has attended many workshops like Cyber security, wareathon, IOT and edc. His area of interest is Networking and DBMS.

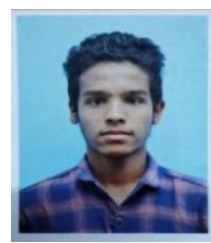

Aakash. $\mathrm{R}$ pursuing his undergraduate degree in $\mathrm{B}$ Tech Information Technology from Kalasalingam Academy of Research and Education. His area of interests are networking and Data mining.

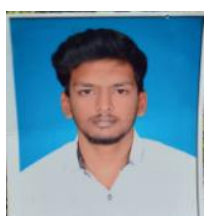

Aniruth $\mathrm{K}$ pursuing his undergraduate degree in $\mathrm{B}$. Tech Information Technology from Kalasalingam Academy of Research and Education. His areas of interests are Database Management systems and Data mining.

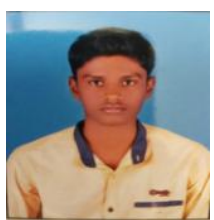

Sarath A pursuing his undergraduate degree in B. Tech Information Technology from Kalasalingam Academy of Research and Education. His areas of interests are Machine Learning and Artificial Intelligence. 